\title{
How Covid-19 opened up questions of sociomateriality in healthcare education
}

\author{
Jennifer Cleland ${ }^{1}$ D Emmanuel Chee Ping $\operatorname{Tan}^{1} \cdot$ Khum Ying Tham $^{1}$. \\ Naomi Low-Beer ${ }^{1}$
}

Received: 4 March 2020 / Accepted: 25 April 2020 / Published online: 6 May 2020

(c) Springer Nature B.V. 2020

A pneumonia of unknown cause was detected in Wuhan, China, and reported to the WHO Country Office in China on 31 December 2019. Labelled initially as a coronavirus, then latterly Covid-19, the outbreak was declared by the World Health Organisation (WHO) as a Public Health Emergency of International Concern on 30 January 2020 and a pandemic on 11th March 2020. As Covid-19 swept around the globe, Health Professions' educators (HPEs) have had to adapt their campus-based and clinical educational provision in a context of rapidly changing circumstances and ongoing uncertainty.

Different countries varied in the speed and nature of their responses to the spread of Covid-19. Our context of Singapore has well-developed protocols for outbreak preparation (MOH 2019) and on 7th February 2020 the Ministry of Health (MOH) risk assessed COVID-19 as "DORSON Orange" (Disease Outbreak Response System Condition) (MOH 2020). This introduced precautionary measures to minimise the risk of transmission of the virus in the country (e.g., daily health checks, stringent contact tracing and quarantining, enhanced focus on hygiene and protection, and segregating groups to contain disease spread). The specific implications of these measures for medical education and teaching were that: students in Singapore's three medical schools were taken out of clinical environments; students could not be taught on a whole or even half class basis; there was reduced availability of clinicians to participate in educational activities, and clinicians who were available could not always attend campus in person because of infection control measures.

Our particular responses to these constraints were multiple. These included: shifting our pedagogy from face-to-face Team-Based Learning (TBL: Rajalingam et al. 2018) to e-TBL delivered online; reducing face-to-face class sizes and running classes repeatedly; and introducing some novel simulations to prepare final year students for postgraduate training. While undoubtedly the pedagogic, technical and operational aspects of what we did will be of interest, particularly to those with a digital learning interest, the focus of this editorial is not to tell you of our adaptations, or ask others to consider how they responded in these uncertain and volatile times. Instead, we position our response to unanticipated disruption as problem-posing rather than problem-solving (Biesta et al. 2019), and a potentially positive driver within the educational research space-if considered appropriately.

Jennifer Cleland

Jennifer.cleland@ntu.edu.sg

1 Lee Kong Chian School of Medicine, Nanyang Technological University, Novena Campus, Singapore 308232, Singapore 
In keeping with the theoretical focus of Advances in Health Sciences Education, to achieve this requires developing our understanding of Covid-19 and resulting education responses in a way which both helps us understand what is happening and produces transferable knowledge. To do so, we draw on a sociomaterial framework, one which specifically assumes that all things are what they are in relation to other things (Law 2009; Gad and Bruun 2010), and the human and non-human are equal in terms of agency (e.g., Fenwick and Edwards 2010; Law 2009).

First, we believe that Covid-19 infection control measures can be framed as a sociomaterial practice. Drawing on the risk assessment literature, DORSCON Orange (and its equivalents in other countries) is founded on the assumption that "evaluating risk is a technical matter to be resolved through objective and rational means to minimize uncertainty" (Wherton et al. 2019, p. 329). Covid-19 risk assessments and precautions were driven by governments, and so sit within wider political and social structures, but their implementation depended on human actions, interactions, and relationships as well as the material properties, affordances and symbolic meanings of precautions. For example, a face mask is a material object, but face masks also have potent sociocultural symbolism (e.g., Siu 2016). These symbolic implications influence how people perceive facemasks, how people perceive those who use them, and suggest that the precise nature of Covid-19 guidance may shift the symbolic significant of facemasks and hence influence people's adoption of facemasks as a precaution against infection. Similarly, focusing on documents as a material component of Covid-19 management, we might consider how official updates on Covid-19, circulated via different mediums, including Whatsapp, text messaging, and more complex documentation, are intermediaries between the macro-actor of government(s) and are all dependent on internet technology and reach. How do different sources of knowledge (e.g., government advice, popular media) impact on people, and act to construct or prevent certain behaviours? What is, and what is not, acceptable behaviour during these strange times is entangled with the material (e.g., communications) and the local (e.g., how people and groups respond to advice).

Moving our focus from societal to educational responses to Covid-19, we had to develop our practices to fit within the boundaries of what was, and was not, allowed or possible (e.g., with limited clinician availability). The medical school leadership had to mobilise individuals (e.g., academic, administrative and IT staff, and students) and existing technologies (e.g., the digital learning platform [LMS]), as well as integrate more technologies into teaching processes (e.g., Whatsapp, Zoom), and these people then collaboratively problem-solved how to address Covid-19 challenges within the constraints of time and the boundaries of available technology. Different systems came together more explicitly than was the case during "business as usual". For example, IT and digital learning colleagues became core rather than invisible (MacLeod et al. 2017), and the systems of teaching and teaching delivery were more obviously tied together, with people and systems relating to one another in new and particular ways (Landri 2012). There was also a very obvious interdependency of users and tools in the network (Cecez-Kecmanovic et al. 2014): for example, we could not deliver teaching or communicate with students without the use of laptops, cameras, Zoom, Whatsapp, etc. IT had a dual materiality, enabling mobilization of teaching across space but it also had design-driven constraints that required the IT and digital learning team to engage in real-time "articulation work" (Kling and Lamb 1999) to make the IT work in the way we needed.

Similarly, our initial observations were that using a combination of Zoom and Whatsapp to deliver teaching offered affordances, opening up new channels of communication and permitting new kinds of interactions. Yet at the same time, it changed some aspects of the 
encounter; for example, students were more likely to pose questions via the chat functionality than verbally. This suggests that the technology was shaping what teachers and students did and hence mediating patterns of teaching and learning. This generates questions relating to, for example: the "choreography" between the human (clinicians, facilitators, content experts, students) and the material (the LMS, Zoom, Whatsapp); how the role and significance of technology in our institution may have shaped our response; and the hardware and videoconferencing may have shaped the interaction between teachers and students, and potentially influenced the process and impact of observation and feedback (Fenwick 2014).

Our examples are just that, but they are apt in the sense that they focus on some of the central sociomaterial notions: affordances; of associations, or entanglements, between elements; how practices might act to construct a particular reality; "knot-working" (collaborative problem-solving; Engestrom et al. 1999) and articulation. We have not provided a comprehensive overview of the many different sociomaterial approaches, key concepts and terms (see Micheal 2017 for a general introduction). Nor have we given a full or even satisfactory description of the situated, complex and messy situation facing many medical educators around the world. These were not our aims in this short commentary. Rather, we make the suggestion that sociomaterial approaches may provide the language and methods to unveil and understand the nature of educational responses to Covid-19.

Rather than merely describing was done during Covid-19, considering how practices, people and things came together to enable educational practices to emerge is a way to "forth particular realities in practice and learning, while highlighting opportunities and entry points for change" (Fenwick 2014, p. 51).

\section{References}

Biesta, G., Filippakou, O., Wainwright, E., \& Aldridge, D. (2019). Why educational research should not just solve problems but should cause them as well. British Educational Research Journal, 45(1), 1-4.

Cecez-Kecmanovic, D., Galliers, R. D., Henfridsson, O., Newell, S., \& Vidgen, R. (2014). The sociomateriality of information systems: Current status, future directions. MIS Quarterly, 38, 809-830.

Engestrom, Y., Engestrom, R., \& Vahaaho, T. (1999). When the center does not hold: The importance of knotworking. In S. Chaiklin, M. Hedegaard, \& U. J. Jensen (Eds.), Activity theory and social practice: cultural-historical approaches (pp. 345-374). Aarhus: Aarhus University Press.

Fenwick, T. (2014). Sociomateriality in medical practice and learning: Attuning to what matters. Medical Education, 48, 44-52.

Fenwick, T., \& Edwards, R. (2010). Actor-network theory in education. London: Routledge.

Gad, C., \& Bruun, Jensen C. (2010). On the consequences of post-ANT. Science, Technology and Human Values, 35(1), 55-80.

Kling, R., \& Lamb, R. (1999). IT and organizational change in digital economies: A socio-technical approach. ACM SIGCAS Computers and Society, 29(3), 17-25.

Landri, P. (2012). A return to practice: Practice-based studies of education. In P. Hager, A. Lee, \& A. Reich (Eds.), Practice, learning and change (pp. 85-100). Dordrecht: Springer.

Law, J. (2009). Seeing like a survey. Cultural Sociology, 3(2), 239-256.

MacLeod, A., Kits, O., Mann, K., Tummons, J., \& Wilson, K. W. (2017). The invisible work of distributed medical education: Exploring the contributions of audiovisual professionals, administrative professionals and faculty teachers. Advances in Health Sciences Education, 22(3), 623-638.

Micheal, M. (2017). Actor-network theory: Trials, trails and translations. London: Sage.

MOH. (2019). Being prepared for a pandemic. Singapore MOH website. https://www.moh.gov.sg/diseasesupdates/being-prepared-for-a-pandemic. Retrieved April 13, 2020.

MOH. (2020). Risk assessment raised to DORSCON Orange. Singapore MOH website. https://www.gov.sg/ article/what-do-the-different-dorscon-levels-mean. Retrieved April 13, 2020. 
Rajalingam, P., Rotgans, J. I., Zary, N., Ferenczi, M. A., Gagnon, P., \& Low-Beer, N. (2018). Implementation of team-based learning on a large scale: Three factors to keep in mind. Medical Teacher, 40(6), $582-588$.

Siu, J. Y. (2016). Qualitative study on the shifting sociocultural meanings of the facemask in Hong Kong since the severe acute respiratory syndrome (SARS) outbreak: Implications for infection control in the post-SARS era. International Journal for Equity in Healt, 15, 73.

Wherton, J., Greenhalgh, T., Procter, R., Shaw, S., \& Shaw, J. (2019). Wandering as a sociomaterial practice: Extending the theorization of GPS tracking in cognitive impairment. Qualitative Health Research, 29(3), 328-344.

Publisher's Note Springer Nature remains neutral with regard to jurisdictional claims in published maps and institutional affiliations. 